\title{
Hypoxanthine as an Indicator of Hypoxia: Its Role in Health and Disease through Free Radical Production
}

\author{
OLA DIDRIK SAUGSTAD \\ Department of Pediatrics, The National Hospital of Norway, Oslo, Norway
}

Hypoxia is a common insult during the perinatal and neonatal period. New and better ways to evaluate hypoxia are needed. In 1975 we demonstrated high concentrations of the purine metabolite hypoxanthine in umbilical cord plasma after intrauterine hypoxia and proposed that hypoxanthine could be used as an indicator of hypoxia (1). Since then a large number of studies have been published dealing with different aspects of hypoxanthine in hypoxia. However, investigators in this field have encountered several methodologic problems: 1) Hypoxanthine leaks rapidly from erythrocytes $(2,3)$; if plasma is not separated promptly from red cells, falsely elevated plasma hypoxanthine concentrations will be found. 2) There are large variations in purine metabolism among species. 3) No clear definition of clinical hypoxia is available. Many authors do not distinguish between the terms hypoxemia and hypoxia, which adds to the confusion. We define tissue hypoxia as: "oxygen deficiency resulting in altered or interrupted energy metabolism" (4). It is important to be aware that hypoxia has two stages. In the first stage it is compensated because the cells are able to meet energy demands through anaerobic metabolism and other mechanisms. (We are not dealing with physiologic adaptation to hypoxia.) In the second stage of hypoxia or uncompensated hypoxia, energy demands are not met and cell injury ensues. At present there are no techniques for distinguishing between these two stages in clinical medicine, and such a distinction would be useful. Theoretically hypoxanthine should only be elevated in uncompensated hypoxia, while $\mathrm{pH}$ and lactate changes occur in compensated hypoxia. It seems, however, that hypoxanthine is also elevated to some extent in uncompensated hypoxia.

Renewed interest in hypoxanthine developed when it was realized that hypoxanthine is a potential free radical generator $(5,6)$. Hypoxanthine seems to play a role in posthypoxic reoxygenation cell injury through oxygen radical production (7) and is therefore involved in the pathogenesis of a number of diseases. Hypoxanthine also modulates a number of other processes because it reacts with benzodiazepine receptors (8) and inhibits phosphodiesterase in the brain (9). Hypoxanthine inhibits the effect of several cytotoxic drugs and may therefore influence treatment with such drugs (10).

Herein we summarize the extensive literature on hypoxanthine published during the last decade and try to answer the question: How useful in clinical medicine are hypoxanthine measurements in plasma and other body fluids? Is hypoxanthine a better marker of hypoxia than lactate or $\mathrm{pH}$ ? Further, we discuss the significance of hypoxanthine as a potential oxygen radical generator and put forward a hypothesis for the pathogenesis of an "oxygen radical disease in neonatology".

Received October 2, 1987; accepted October 6, 1987

Correspondence O. D. Saugstad, M.D., Department of Pediatrics, Rikshospitalet, 0027 Oslo 1, Norway.

\section{METABOLISM}

Hypoxanthine is a breakdown product of ATP. Cells try to maintain a high energy charge even if ATP concentration falls and the energy level decreases (11). The formula for the energy charge (EC): $\mathrm{EC}=\mathrm{ATP}+0.5 \mathrm{ADP} / \mathrm{AMP}+\mathrm{ADP}+\mathrm{ATP}$ indicates that EC can be kept high during ATP deficiency by reducing the concentration of AMP; this is exactly what happens. In hypoxia there is an accelerated breakdown of AMP to hypoxanthine. Figure 1 illustrates several important aspects of hypoxanthine metabolism in hypoxia. Normally about $90 \%$ of the hypoxanthine formed is reutilized through the salvage pathway and inosine monophosphate (IMP) is formed. Phosphoribosylpyrophosphate (PRPP) and ATP are required for the synthesis of IMP from hypoxanthine by the enzyme hypoxanthine guanine phosphoribosyl transferase (HGPRT). This is the enzyme missing in the Lesch-Nyhan syndrome (12). The rate of transformation of hypoxanthine to IMP is reduced in hypoxia, as is the further oxidation of hypoxanthine to xanthine and uric acid by xanthine oxidase. This enzyme is mainly found in the liver and small intestine of the human, although there may be low concentrations in other tissues. In other species including the rat, dog, cat, and sheep, xanthine oxidase is also in high concentration in the lungs (13). Experiments measuring hypoxanthine in plasma of animals with lung xanthine oxidase will be difficult to interpret because the lungs have a formidable capacity to clear hypoxanthine from the circulation. It might be difficult to detect hypoxanthine in arterial plasma even during profound hypoxia. Xanthine oxidase is synthesized as xanthine dehydrogenase (type D) and this form accounts for about $90 \%$ of the total activity in nonhypoxic tissue (14). During hypoxia and ischemia the dehydrogenase form is converted to the oxidase form (type $O$ ). This conversion may result from a protease activated by the high calcium concentration found in the cytosol of hypoxic cells (15).

In most mammals, the main exception being man and higher apes where uric acid is the end product of purine catabolism, uric acid is further oxidized by uricase to allantoin. In adult humans approximately two-thirds of the uric acid is eliminated through the kidneys and one-third through the gastrointestinal tract (16). Renal handling of uric acid seems to involve four steps: glomerular filtration, tubular reabsorption, active secretion, and postsecretory reabsorption (17). The mechanism of xanthine excretion in the kidney is similar to that of uric acid, whereas hypoxanthine is eliminated mainly by filtration along with other purine bases $(18,19)$. Xanthine excretion is reduced by uricosuric drugs whereas hypoxanthine seems to be unaffected by these agents (19). In adults the hypoxanthine urinary output is on the average 1.0 (range $0.6-1.4) \mu \mathrm{mol} / \mathrm{kg} / \mathrm{day}(20)$ as compared with a comparable output of 1.1 (range $0.7-1.6) \mu \mathrm{mol} / \mathrm{kg} /$ day on the 1st day of life. This output slowly decreases over the subsequent days and a mean output of 0.7 (range $0.1-1.5$ ) $\mu \mathrm{mol} /$ 


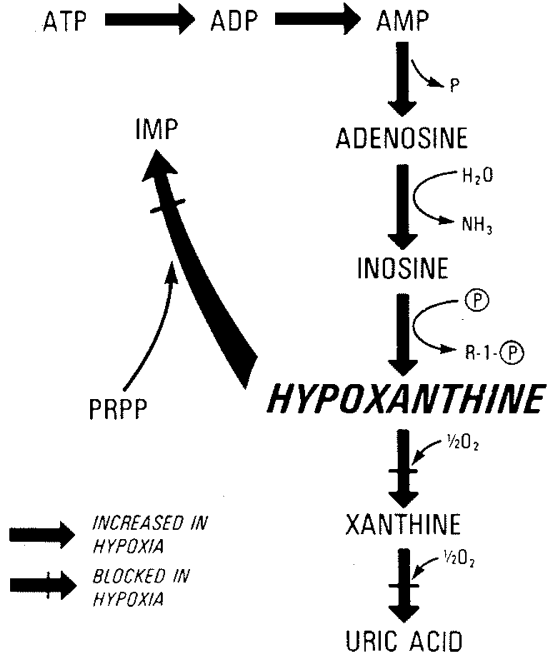

Fig. 1. Schematic outline of adenine nucleotide metabolism. In hypoxia AMP is degraded to hypoxanthine via adenosine and inosine. Salvage of hypoxanthine to IMP is reduced as is the further catabolism to uric acid when lack of oxygen. From Saugstad and Gluck (71) used with permission.

$\mathrm{kg} /$ day on the $3 \mathrm{rd}$ day of life was measured (21). Hypoxanthine clearance in normal adults range between $40-60 \mathrm{ml} / \mathrm{min} / 1.73$ $\mathbf{M}^{2}$ (19). Plasma half-times in adult pigs and fetal lambs after hypoxia are approximately 40 and $30 \mathrm{~min}$ respectively $(22,33)$. Plasma half-times of hypoxanthine in newborn babies and adults are still not known with certainty.

\section{METHODS}

Methods to measure hypoxanthine reliably in plasma were not available until the middle of the last decade, limiting the information about hypoxanthine in pathophysiologic conditions. The first spectrophotometric methods for measurements of plasma hypoxanthine in the late 1940s and early 1950 s were inaccurate, laborious, and required large amounts of blood $(24,25)$. When hypoxanthine was measured for the first time in umbilical cord plasma after uncomplicated deliveries in 1972 (26), $40 \mathrm{ml}$ of blood were required (26). The introduction of the $\mathrm{pO}_{2}$ method a few years later made it possible to measure hypoxanthine levels in plasma and other body fluids systematically (3). This method is based on the principle that oxygen is consumed when hypoxanthine is oxidized to xanthine and urate. The hypoxanthine concentration can be calculated by measuring the fall in $\mathrm{pO}_{2}$ in the solution after addition of xanthine oxidase. The method is simple, inexpensive, and rapid, requiring not more than $200 \mu \mathrm{l}$ plasma. A drawback is that half the xanthine present is measured as hypoxanthine resulting in a somewhat high hypoxanthine value. The xanthine/hypoxanthine ratio in plasma and other body fluids is normally $20-45 \%(27,28)$ and decreases to between 5 and $12 \%$ in hypoxia $(27,29)$. Thus the error becomes almost negligible, at least in the hypoxic state. The $\mathrm{pO}_{2}$ method is not sensitive at very low hypoxanthine concentrations (less than $3-$ $5 \mu \mathrm{mol} /$ liter).

Fluorimetry $(30,31)$ and high-performance liquid chromatography (HPLC) $(28,32-35)$ provide methods with greater sensitivity. Although several other methods have been described, $\mathrm{pO}_{2}$, fluorimetric, or HPLC methods are the most generally used. The fluorimetric method also adds half of the xanthine present to the hypoxanthine. In one study where this method was compared with the $\mathrm{pO}_{2}$ method, the fluorimetric technique had a higher precision and lower blood volumes were required $(50 \mu \mathrm{l})(36)$. Plasma hypoxanthine measurements have been compared using the $\mathrm{pO}_{2}$ and HPLC methods in three studies (37-39), and cor- relation coefficients between the two methods ranged between 0.88 and 0.99 . In summary, the $\mathrm{pO}_{2}$ method is less expensive, simpler, and faster than HPLC method, whereas HPLC is more sensitive, especially at low concentrations. HPLC also separates hypoxanthine and xanthine in addition to other purines.

\section{STUDIES ON ISOLATED ORGANS}

The first studies demonstrating an elevation of hypoxanthine in hypoxia were performed on isolated organs about $25 \mathrm{yr}$ ago. The fundamental studies of Berne (40) on the perfusate from isolated hypoxic cat myocardium, and by Gerlach et al. (41) assessing the perfusate from isolated hypoxic kidneys showed an increased output of purine metabolites. Berne and Rubio (42) were interested mainly in studying the effect of adenosine on the circulation. Since then other groups have reported high hypoxanthine concentrations in hypoxic tissues including kidney (43), liver (44), brain (44-46), myocardium $(44,47)$, intestine (48), lungs (49), and placenta (50). In placental tissue the hypoxanthine concentration was correlated with the energy charge and a negative correlation of 0.79 was found (50). This correlation therefore demonstrates that the hypoxanthine concentration accurately reflects the energy status of the cell, which is exactly what we are trying to quantify when diagnosing hypoxia. The hypoxanthine concentration was recently measured in food and used as an index of food quality (51).

\section{ANIMAL STUDIES}

We measured plasma hypoxanthine concentrations in hypoxemic and hypotensive dogs $(52,53)$, not knowing that xanthine oxidase was present in their lungs. There were low hypoxanthine concentrations in arterial plasma even in profound hypoxia whereas high levels were measured in the inferior caval venous plasma. In dogs with endotoxic shock there was a dramatic washing out of hypoxanthine during resuscitation with volume expansion. In the course of 10-15 min venous hypoxanthine levels were raised from zero to more than $100 \mu \mathrm{mol} / \mathrm{liter}$. In arterial plasma there was also a substantial elevation of hypoxanthine during this procedure (54). In dogs with respiratory arrest hypoxanthine increased linearly in cerebrospinal fluid during the $18 \mathrm{~min}$ that the experiments lasted (55).

We studied pigs because pigs and humans lack lung xanthine oxidase. Hypoxia was induced by allowing the pigs to breathe 6 or $7 \%$ oxygen in nitrogen. A linear increase of plasma hypoxanthine with duration of hypoxemia was found, and there was no difference between arterial and venous plasma. There were good correlations between hypoxanthine and lactate, base deficit and $\mathrm{pH}(7,22)$. There was also a direct relationship between survival time and increase in plasma hypoxanthine. Survival time correlated negatively with the rate of hypoxanthine increase $(r=$ $-0.62)$. All animals died when hypoxanthine exceeded 125 $\mu \mathrm{mol} /$ liter. The increase of hypoxanthine therefore reflected the prognosis of acute hypoxia in contrast to base deficit (7).

In the exteriorized hypoxic fetal lamb Thiringer et al. (23) demonstrated a rapid increase in plasma hypoxanthine concentrations. Figure 2 shows the relation between plasma hypoxanthine concentration and duration of hypoxemia. As in adult pigs, there were high correlations with lactate $(r=0.83)$, base deficit $(r=0.87)$, and $\mathrm{pH}(r=0.90)$. Hypoxanthine was cleared from plasma after reversal of hypoxia with a half-time of $30 \mathrm{~min}(23)$. Subsequent to these experiments it became apparent that the lungs of newborn sheep, by contrast to fetal lambs with minimal pulmonary perfusion, very efficiently clear hypoxanthine, probably because they have high levels of xanthine oxidase. This might explain why one group of investigators found a biphasic increase of plasma hypoxanthine concentration when studying hypoxic newborn lambs (56).

Thiringer et al. (57) have shown that the brain of fetal sheep does not release hypoxanthine during either normoxia or even 
in mild hypoxia. Hypoxanthine is released only in severe hypoxia, indicating that the fetal brain has a high threshold for degrading its energy-rich intracellular purines. This could be due to the fact that the brain has a high concentration of the enzyme HGPRT which may constitute part of hypoxic defenses of the brain. There was a linear correlation between cerebral arteriovenous differences of hypoxanthine in the fetal lamb and somatosensoric-evoked potential signals. The contribution of hypoxanthine from different organs of the exteriorized fetal lamb was also studied (58). Hypoxanthine was released from the liver even during normoxia which was quite surprising since the bulk of the xanthine oxidase was found in this organ. A substantial output was found in hypoxia from the liver as well as the myocardium. In contrast, the hind leg produced little hypoxanthine in hypoxia. The placenta cleared hypoxanthine efficiently both in normoxia and hypoxia (58). On the basis of this study it was therefore concluded that the liver and myocardium were the main producers of hypoxanthine in fetal hypoxia.

\section{PLASMA HYPOXANTHINE IN MAN}

The first clinical study demonstrating augmented hypoxanthine levels in hypoxia was performed with the $\mathrm{pO}_{2}$ method in umbilical cord plasma (1). In this study the normal hypoxanthine concentration was found to range between 0 and $11 \mu \mathrm{mol} /$ liter,
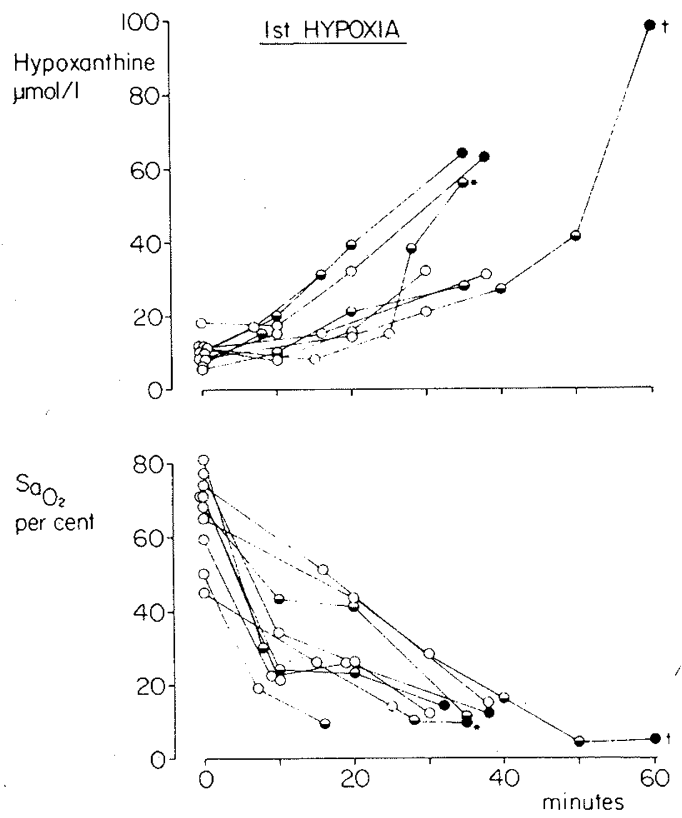

Fig. 2. The time relationship of plasma hypoxanthine concentration and $\mathrm{SaO}_{2}$ in 10 exteriorized fetal lambs. Hypoxia was induced by ventilation the ewe with $16 \% \mathrm{O}_{2} . \mathrm{O}, \mathrm{pH}>7.30 ; \ominus, \mathrm{pH} 7.15-7.29 ; \bullet, \mathrm{pH}$ $<7.15$. From Thiringer et al. (23) used with permission. with a mean of $5.8 \mu \mathrm{mol} / \mathrm{liter}$. The mean level in hypoxic babies was $25 \mu \mathrm{mol} /$ liter, significantly higher than the nonhypoxic values. Subsequently others have measured the plasma hypoxanthine levels in umbilical cord blood in normal and hypoxic babies (Table 1) $(37,38,59-64)$. All investigators found higher hypoxanthine values in hypoxic than in nonhypoxic babies, even though this elevation was not significant in two of the studies $(37,59)$. There is a remarkable agreement among investigators as to the normal level of umbilical cord hypoxanthine plasma, e.g. 4 to $8 \mu \mathrm{mol} /$ liter, even when different methods for measuring hypoxanthine were used. A positive difference was found between umbilical arterial and venous levels in two studies (37, 59), indicating net transfer of hypoxanthine from the fetus to the mother. However, no significant differences in umbilical venoarterial levels of hypoxanthine and xanthine were reported in another study $(65)$. In these three studies $(37,59,65)$ the mean normal hypoxanthine concentrations were rather high, indicating that plasma was not separated from plasma quickly enough. The reliability of these data can therefore be questioned.

In general umbilical cord hypoxanthine levels can be used to distinguish between hypoxia and nonhypoxia. We found a few patients with mild hypoxia having hypoxanthine concentrations in the normal range but we have never found a nonhypoxic patient with elevated values (62). In the most thorough study to date on umbilical cord plasma, hypoxanthine was determined with the $\mathrm{pO}_{2}$ method in 141 newborn babies (60). Fifty babies suffering from mild or severe intrauterine hypoxia were compared with 29 babies from high risk deliveries but without clinical or biochemical signs of hypoxia and with 62 babies from normal deliveries. The mean hypoxanthine concentration of hypoxic patients was $16.6 \mu \mathrm{mol} / \mathrm{liter}$, a value significantly higher than that of normal babies $(5.7 \mu \mathrm{mol} /$ liter $)$ or babies at risk $(8.7 \mu \mathrm{mol} /$ liter). From this study a normal upper limit of hypoxanthine in cord blood was defined as $14 \mu \mathrm{mol} /$ liter.

When correlating hypoxanthine and Apgar score a weak but significant negative correlation of $r=-0.33(p<0.05)$ was found. The correlation between hypoxanthine and lactate concentrations was $r=0.62$ for hypoxic babies. Two babies in this series developed spastic paresis, both of whom had normal Apgar scores but high hypoxanthine concentrations. One newborn baby with cardiac arrest had a hypoxanthine level after resuscitation exceeding $200 \mu \mathrm{mol} /$ liter. This study suggests that plasma hypoxanthine concentrations are a better predictor of outcome than Apgar scores or lactate (60). In a recent study, Pietz et al. (63) found significantly higher hypoxanthine levels in cord plasma of hypoxic as contrasted with nonhypoxic babies. Five of six babies who died had hypoxanthine levels exceeding 2 SEM above the mean for nonhypoxic controls. These authors conclude that hypoxanthine concentration should be used as the new "gold" standard of hypoxia.

Immediately postpartum, hypoxanthine is washed into the circulation, such that peak values are found 10 to $20 \mathrm{~min}$ postpartum (Fig. 3). After this period the hypoxanthine concentration quickly decreases to levels between 0 and $5 \mu \mathrm{mol} / \mathrm{liter}$.

Table 1. Hypoxanthine concentration ( $\mu$ mol/liter) in venous, arterial, or mixed umbilical cord plasma (SD)

\begin{tabular}{|c|c|c|c|c|}
\hline \multirow[b]{2}{*}{ Reference } & \multicolumn{2}{|c|}{ Mean or median concentration } & \multirow[b]{2}{*}{ Method } & \multirow[b]{2}{*}{$p$} \\
\hline & Control & Hypoxia & & \\
\hline Saugstad (1) & $5.8 \pm 3.0$ & $25.0 \pm 18.0$ & $\mathrm{pO}_{2}$ & $<0.01$ \\
\hline Guicheney et al. (37) & $8.5 \pm 5.4$ & $15.4 \pm 15.5$ & HPLC & NS \\
\hline O'Connors et al. (38) & $4.2 \pm 2.9$ & $17.9 \pm 28.6$ & HPLC & $<0.025$ \\
\hline Bratteby and Swanström (66) & $5.3 \pm 3.3$ & & $\mathrm{pO}_{2}$ & \\
\hline Lipp Zwahlen et al. (59) & $14.4 \pm 4.7$ & $16.4 \pm 5.1$ & $\mathrm{pO}_{2}$ & NS \\
\hline Thiringer $(60)$ & $5.7 \pm 5.8$ & $16.6 \pm 14.9$ & $\mathrm{pO}_{2}$ & $<0.01$ \\
\hline Merchurova et al. (61) & $13.1 \pm 4.5$ & $23.0 \pm 10.7$ & $\mathrm{pO}_{2}$ & $<0.01$ \\
\hline Saugstad et al. (62) & $6.3 \pm 6.6$ & $14.1 \pm 10.9$ & $\mathrm{pO}_{2}$ & $<0.005$ \\
\hline Pietz et al. (63) & $8.7 \pm 3.4$ & $19.2 \pm 5.8$ & $\mathrm{pO}_{2}$ & $<0.005$ \\
\hline Issel et al. (64) & $5.1 \pm 1.8$ & $10.0 \pm 3.4$ & Fluorimetric & $<0.01$ \\
\hline
\end{tabular}




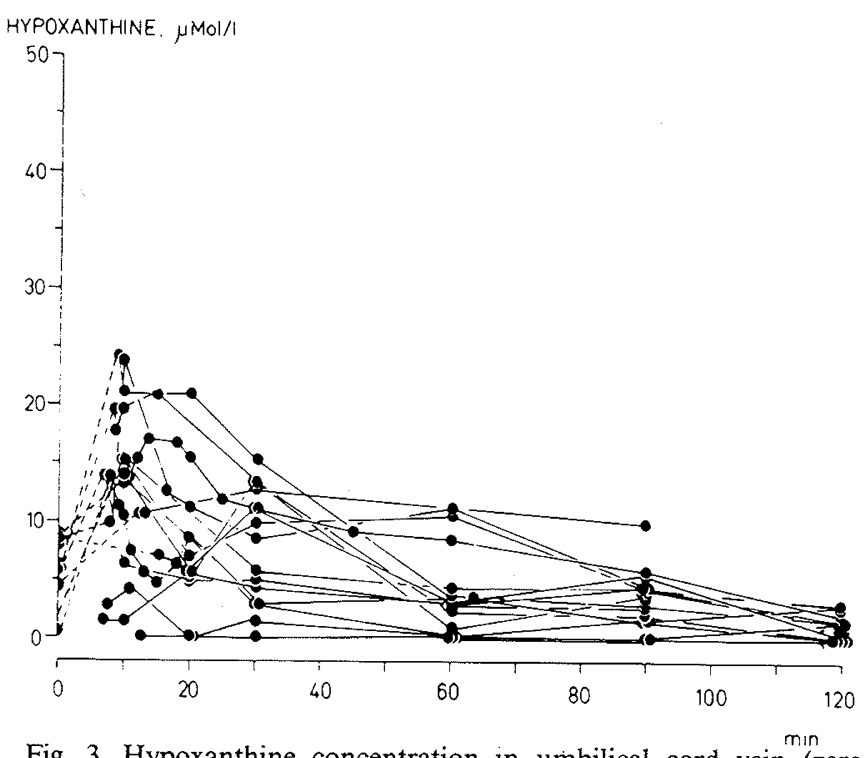

Fig. 3. Hypoxanthine concentration in umbilical cord vein (zero time) and arterial plasma in normal infants during the first $120 \mathrm{~min}$ after birth. From Bratteby and Swanström (66) used with permission.

The same pattern was found in nonhypoxic as in hypoxic patients; however, the peak value reached higher levels in the hypoxic patients $(66,67)$. These data show that the best way to assess intrauterine hypoxia by plasma hypoxanthine determinations is by serial measurements. In both full-term and premature nonhypoxic newborn babies the hypoxanthine level declines during the first days of life. The mean value during the first 12 to $36 \mathrm{~h}$ of life in full-term babies is $5.5 \mu \mathrm{mol} /$ liter with a range of $2.7-11.2 \mu \mathrm{mol} / \mathrm{liter}$; at 3 and 5 days of life the mean levels were 3.2 and $1.8 \mu \mathrm{mol} /$ liter, respectively. Premature babies have hypoxanthine values similar to term infants.

The correlation between hypoxanthine and lactate in eight hypoxic babies was $r=0.64, p<0.001$ ) (68). High hypoxanthine levels were measured in preterm babies with respiratory distress syndrome (RDS) and with congenital heart lesions $(69,70)$. In babies subsequently dying of RDS values as high as $100 \mu \mathrm{mol} /$ liter were found (69). We measured the hypoxanthine concentrations in arterial plasma of sick newborn babies and found correlations between hypoxanthine and $\mathrm{pH}$ of $r=-0.80$, between hypoxanthine and base deficit of $r=0.78$, and between hypoxanthine and $\mathrm{paO}_{2}$ of $r=-0.64$. The hypoxanthine concentrations were a better predictor of survival than were the other variables. Hypoxanthine also correlated better than $\mathrm{pH}$ or base deficit with short-term complications such as intracranial hemorrhage (71).

Plasma hypoxanthine has been used as a marker of hypoxia in adults as well as in newborns. High levels were found in mixed venous blood in a group of critically ill patients, the majority of whom suffered from the adult RDS. By contrast to blood gases, which were not helpful in predicting survival, hypoxanthine and other ATP degradation products proved to be good indicators of survival (72). When aortic flow was interrupted by cross-clamping during surgery, the hypoxanthine concentration increased and correlated well $(r=0.85)$ with clamping time, in contrast to lactate levels and changes in acid-base status (73). Augmented plasma hypoxanthine concentrations have also been found in diabetic ketoacidosis with rhabdolysis (74). In patients undergoing hemodialysis, the plasma hypoxanthine concentration increased simultaneously with decreases in arterial oxygen tension, demonstrating that routine hemodialysis, even in stable patients, is associated with some cellular hypoxia (76). Plasma hypoxanthine is high after exercise $(19,27,77)$.

\section{HYPOXANTHINE IN URINE}

In newborn infants the urinary hypoxanthine excretion during the first $24 \mathrm{~h}$ of life is three to four times higher in babies suffering from intrauterine hypoxia compared with nonhypoxic babies (78). There was also a high correlation between the urinary hypoxanthine excretion and the hypoxanthine/creatinine ratio in the urine $(r=0.70)(79)$. Such a ratio can be determined on random urine samples, simplifying the collection of urine. Even on the 2 nd day of life an elevated ratio was found in babies with intrauterine hypoxia. Infants who are neurologically abnormal more than $48 \mathrm{~h}$ postpartum have a higher hypoxanthine/creatinine ratio than hypoxic infants who subsequently developed normally $(79,80)$. In adult patients resuscitated after cardiac arrest, urinary excretion of hypoxanthine increased 6-fold the first $2 \mathrm{~h}$ after the cardiac arrest (81). In adult hypotensive patients there was a significant elevation of hypoxanthine + xanthine/ creatinine clearance during periods of hypotension as compared with normotensive periods (82).

\section{HYPOXANTHINE IN CEREBROSPINAL FLUID}

Elevated levels of hypoxanthine in cerebrospinal fluid have been observed in patients with the Lesch-Nyhan syndrome (83). We found high hypoxanthine concentrations in the cerebrospinal fluid of newborn babies who suffered from hypoxia, as well as in children after convulsions (84). Children with convulsions of several types had elevated cerebrospinal fluid hypoxanthine concentrations. The highest levels were observed 30 to 120 min after the convulsion $(85,86)$. High hypoxanthine concentrations also have been found in children suffering from bacterial meningitis $(84,86)$. After hypoxia, a tremendous rise in cerebrospinal fluid hypoxanthine concentrations has been reported in children and adults, and such elevations can be detected for as long as 1 to 2 days after hypoxia (87). The mean normal cerebrospinal fluid hypoxanthine concentration seems to range between 0 and 3-5 $\mu \mathrm{mol} /$ liter in most studies $(84,86-88)$, whereas after severe intrauterine hypoxia levels up to $700 \mu \mathrm{mol} /$ liter have been found (87). Mortality tends to be high in patients with high levels, and in one study the surviving babies with cerebrospinal fluid con-

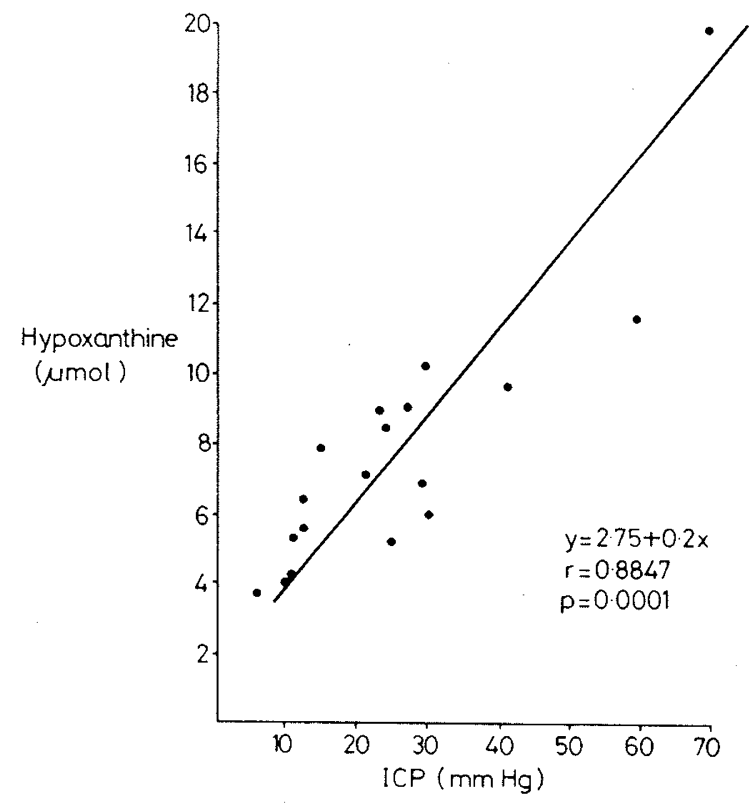

Fig. 4. Correlation of cerebrospinal fluid hypoxanthine concentration against mean intracranial pressure $(I C P)$ over a 1 -min period during rapid eye movement sleep in 18 hydrocephalic children. From Levin et al. (89) used with permission. 
centrations of more than $50 \mu \mathrm{mol} /$ liter had residual cerebral damage (87).

We measured the cerebrospinal fluid hypoxanthine concentration in newborn babies with hydrocephalus. The size of the ventricles was estimated by ultrasound, and high hypoxanthine concentrations were found when the ventricles were large. The concentration then decreased after lumbar tapping or shunting of the ventricles (88). We therefore suggested that the cerebrospinal fluid hypoxanthine concentration might be used as a guide to timing the treatment of hydrocephalus. Levin et al. (89) reported a highly significant correlation between the hypoxanthine concentration and the intracranial pressure $(r=0.88, n=$ 18 ) in hydrocephalic children (Fig. 4). This correlation supports the contention that hypoxanthine cerebrospinal fluid concentrations can be used to evaluate intracranial pressure. A third study recently confirmed these data showing a significant decrease in cerebrospinal fluid hypoxanthine concentration values after implantation of a shunt in nine hydrocephalic children with shunt failures (90).

Adult patients requiring cardiac resuscitation had cerebrospinal fluid hypoxanthine concentrations three times as high (18.7 $\mu \mathrm{mol} / \mathrm{liter})$ as the mean level $(6.3 \mu \mathrm{mol} / \mathrm{liter})$ in reference patients. Hypoxanthine was measured 0 to $5 \mathrm{~h}$ after resuscitation and decreased to normal levels within $20 \mathrm{~h}$. However, in patients who remained comatose after resuscitation the mean hypoxanthine concentration was as high as $51.7 \mu \mathrm{mol} /$ liter (91).

\section{HYPOXANTHINE IN OTHER BODY FLUIDS}

High hypoxanthine concentrations were found in the amniotic fluid of babies suffering from intrauterine hypoxia (92). In the corpus vitreum humor we found that hypoxanthine concentrations were stable up to $72 \mathrm{~h}$ postmortem (93). In adults who died from respiratory depression there were very high concentrations of hypoxanthine in the vitreous humor compared with values after acute death (93). The hypoxanthine concentration in vitreous humor seems to be about 10 times higher than the concentration in plasma even in the absence of hypoxia. In premature babies dying from hypoxia caused by RDS, high levels were found in the vitreous humor, values about eight to nine times higher than in babies dying without preceding hypoxia. Also, in these neonates there was a significant correlation between the vitreous humor hypoxanthine concentration and the duration of $\mathrm{PaO}_{2}$ values less than $40 \mathrm{~mm} \mathrm{Hg}(5.3 \mathrm{kPa})(29)$. Hypoxanthine determinations of the vitreous humor might therefore be used to evaluate whether death was preceded by hypoxia.

\section{PLASMA HYPOXANTHINE CONCENTRATIONS IN CANCER}

Adult patients with malignant lymphomas pretreated with the xanthine oxidase inhibitor allopurinol had a marked rise in hypoxanthine concentration $24 \mathrm{~h}$ after the onset of chemotherapy (Fig. 5). About $1 \mathrm{wk}$ after the start of chemotherapy, values had returned to pretreatment levels (94). High plasma hypoxanthine concentrations recently were found in adults with leukemia (10) and in urine of children with leukemia (95). These findings may be of clinical interest for two reasons: 1) because it has been shown that hypoxanthine inhibits the effect of certain cytotoxic drugs $(10,96)$, and 2 ) because hypoxanthine is a potential oxygen radical generator. We know that several cytotoxic drugs exert their action through free radical production. High hypoxanthine concentrations could, in an uncontrolled way, potentiate both beneficial and adverse effects of these drugs.

\section{NEUROCHEMICAL ASPECTS OF HYPOXANTHINE}

Hypoxanthine has aroused particular interest because of its putative role as an endogenous ligand of benzodiazepine receptors in the brain and its possible role in termination of epileptic

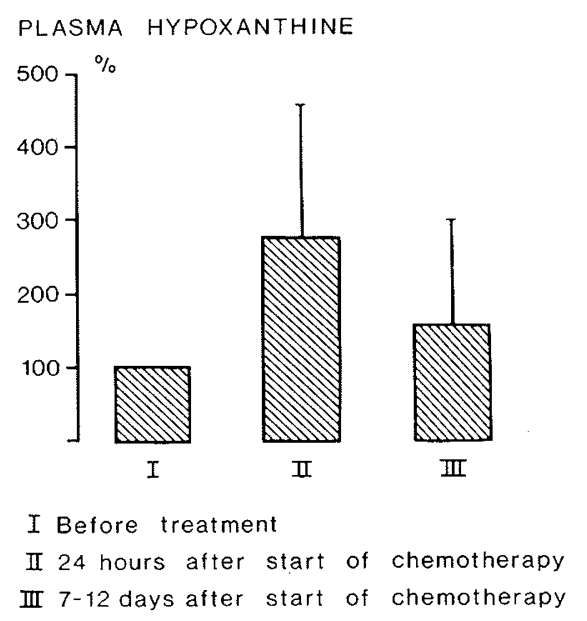

Fig. 5. Plasma hypoxanthine concentration in seven patients with malignant lymphomas pretreated with allopurinol. The initial level of each patient is set to $100 \%$. Twenty-four $\mathrm{h}$ after the start of chemotherapy the hypoxanthine level was significantly elevated in mean (273\%) compared with initial levels $(p<0.01)$. After approximately 1 wk hypoxanthine concentrations had decreased to a level not significantly different from initial levels (SD is given). From Saugstad (94) used with permission.

activity $(8,97,98)$. It is also an inhibitor of cyclic nucleotide phosphodiesterase in bovine brain tissue (9). Recently the cerebrospinal fluid hypoxanthine concentration was measured in patients with major depressive disorders. The hypoxanthine concentration was positively correlated with monoamine metabolites and norepinephrine metabolites (99). The same investigators found that a suicidial tendency was related to low levels of hypoxanthine in the cerebrospinal fluid, whereas there existed a positive relationship between hypoxanthine levels and decreased appetite in such patients (100). There is at present a growing interest in the role of purines in neurotransmission (101).

\section{HYPOXANTHINE AS AN OXYGEN RADICAL GENERATOR}

A new and fascinating aspect of hypoxanthine relates to the discovery that it is a potential oxygen-free radical generator $(5$, 6). Free radicals are unstable compounds with one unpaired electron in their outer orbit. They are highly reactive, injuring cell membranes by peroxidation of unsaturated fatty acids. Oxygen radicals are created in many processes where oxygen is involved. When hypoxanthine $(\mathrm{Hx})$ is oxidized to uric acid in the presence of xanthine oxidase, the superoxide radical $\mathrm{O}_{2}^{-}$is formed:

$$
\mathrm{Hx}+\mathrm{O}_{2} \rightarrow \text { uric acid }+\mathrm{H}_{2} \mathrm{O}_{2}+\mathrm{O}_{2}^{-}
$$

The superoxide radical can further react with the hydrogen peroxide produced by this process with the formation of the highly reactive hydroxyl radical:

$$
\mathrm{H}_{2} \mathrm{O}_{2}+\mathrm{O}_{2}^{-} \rightarrow \mathrm{OH} \cdot+\mathrm{OH}^{-}
$$

Recently it has been shown that oxygen radicals are involved in a series of disease processes. Possibly oxygen radicals formed through the hypoxanthine-xanthine oxidase system are a cause of the dramatic tissue injury seen after hypoxia in the reoxygenation period. This so-called "oxygen paradox" has been difficult to explain until recently. Because hypoxanthine accumulates in hypoxia and because oxygen is subsequently administered as treatment, large amounts of oxygen radicals can be assumed to be formed (7). Previous authors have suggested that some unknown substance(s) accumulating in hypoxia may be injurious to the tissues after hypoxia. Fridovich (102) stated: "Perhaps, the damage is really not sustained during hypoxia, but rather when 
normal oxygenation is subsequently reestablished. Thus we can suppose that reductants accumulate during hypoxia, much as homogentisate accumulates in hepatocytes in hypoxia. The reductants need not, in themselves, be damaging, but since they can autoxidize, they could generate a burst of $\mathrm{O}_{2}^{-}$and $\mathrm{H}_{2} \mathrm{O}_{2}$ in reoxygenation. The damage would then be caused by a temporary production of oxygen radicals, at a rate greater than could be accommodated by the defenses."

We had already suggested that the unknown accumulated metabolite was hypoxanthine (7) and other authors have subsequently confirmed this $(15,103,104)$. The term "ischemiareperfusion injury" has been introduced for this phenomenon $(15,103)$. It is a term that could be misleading because there are so many uncontrolled factors, in addition to hypoxanthine washout, during the reperfusion process. A better term for this phenomenon may be "posthypoxic-reoxygenation injury."

To test this hypothesis we performed an experiment in which young rats were infused intravenously with hypoxanthine while breathing $100 \%$ oxygen for $48 \mathrm{~h}$. Compared with control animals breathing $100 \%$ oxygen and infused with glucose, or animals infused with hypoxanthine but breathing room air, we found hemorrhage and edema in the lungs (105). In lung lavage there was a many-fold increase in protein content. Despite a normal surfactant phospholipid profile, surfactant function was destroyed. This could be due to inactivation of surfactant either by direct peroxidation or by the presence of surfactant inhibitor. These data show that during these experimental conditions the combination of hypoxanthine and oxygen is toxic to the lungs by contrast to hypoxanthine or oxygen alone. The instillation of xanthine oxidase into the tracheas of guinea pigs reduces lung thorax compliance quite dramatically, an effect that can partly be prevented by superoxide dismutase (106).

Superoxide dismutase, a superoxide radical scavenger, and allopurinol, a xanthine oxidase inhibitor, protect against reperfusion injury in the intestine of cats and in the isolated rat heart $(107,108)$. In separated loops of the small intestine of rats where xanthine oxidase and hypoxanthine were instilled in combination, severe hemorrhage and edema ocurred. The hypoxanthinexanthine oxidase system starts prostaglandin synthesis in the intestinal wall (109). This is in accordance with present knowledge that free radicals can trigger arachidonic acid synthesis (110). In one study where isolated rabbit lungs were perfused with a combination of xanthine oxidase and a purine, large amounts of thromboxane B2 were released and pulmonary vasoconstriction occurred (111).

\section{AN HYPOTHESIS FOR AN OXYGEN RADICAL DISEASE IN NEONATOLOGY}

It seems likely that production of oxygen radicals by the hypoxanthine-xanthine oxidase system after reoxygenation after hypoxia contribute importantly to a series of diseases in newborn babies. Animal studies document that the concentrations of the oxygen radical scavengers superoxide dismutase, glutathione peroxidase, and catalase are low before term and reach peak values around term (112-114). The preterm baby therefore has less defense against free radicals produced for example by the hypoxanthine-xanthine oxidase system as compared with the term baby. Bronchopulmonary dysplasia might be caused by such a mechanism. The lungs of preterm babies are probably exposed to higher hypoxanthine concentrations than a normal lung; in addition the former is often exposed to supplemental oxygen. Subsequently a higher flux of oxygen radical production might occur. Necrotizing enterocolitis could be, at least partly, caused by the same mechanism. The intestine contains large amounts of xanthine oxidase (13). Most of the described etiological factors in the development of necrotizing enterocolitis are conditions where oxygen radicals may be produced in excess by the hypoxanthine-xanthine oxidase system. One etiologic factor for necrotizing enterocolitis frequently mentioned is blood transfusion,

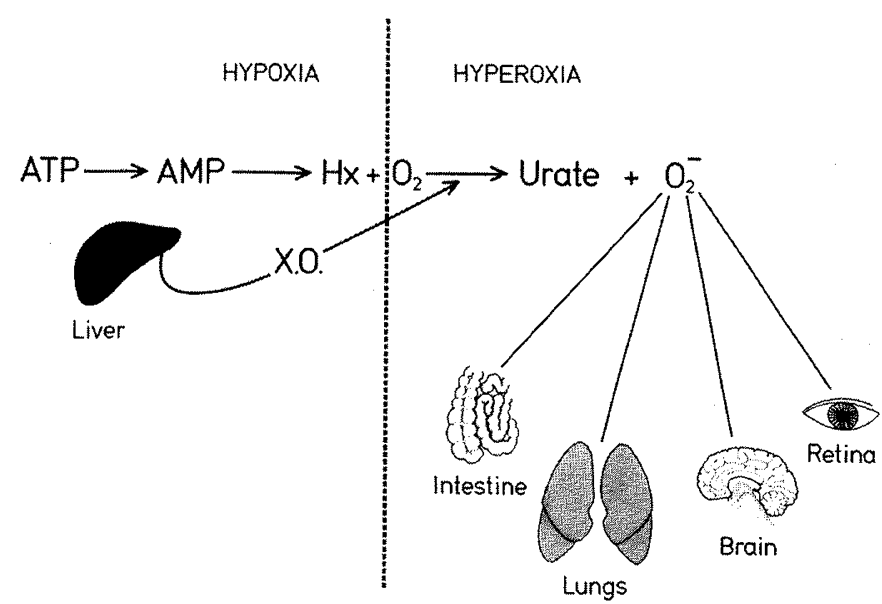

Fig. 6. Proposed mechanism of posthypoxic-reoxygenation injury. During hypoxia hypoxanthine is accumulated and xanthine oxidase $(X . O$.$) is released from the liver into the circulation. During reoxygena-$ tion oxygen radicals are formed that might injure several organs. From Saugstad (117) used with permission from the author and W. B. Saunders.

and it is of interest that transfused blood has extremly high concentrations of hypoxanthine $(2,3,115)$. Retinopathy of prematurity may also be caused by the same mechanism. It has long been known that hyperoxia cannot be the only etiologic factor in the development of this disease (116). One additional factor could be hypoxanthine, which we have found in extremly high concentrations in the eyes of babies dying of RDS (29). Whether there is any xanthine oxidase present in the retinal tissue or in the general circulation during hypoxia, is still unknown.

Figure 6 summarizes the concept (117) that hypoxanthine accumulates in hypoxia. Xanthine dehydrogenase is tranformed to xanthine oxidase in hypoxia and we hypothesize that it is simultaneously released from the liver into the circulation. During reoxygenation, oxygen radicals are formed in excess and different organs are attacked. Thus we may not be dealing with different diseases in bronchopulmonary dysplasia, necrotizing enterocolitis, or retinopathy of prematurity. Therefore, they may be different aspects of one disease; an "oxygen radical disease in neonatology," caused by a common pathogenic mechanism. However, the clinical manifestation of this disease differs according to which organ is most severely affected. Such a general hypothesis for the pathogenesis of these conditions may help us to understand a series of features that have been difficult to explain. However, more experimental and clinical data are required before the hypothesis can be fully accepted.

\section{CONCLUSION}

There is now a large body of literature demonstrating that hypoxanthine is a sensitive indicator of hypoxia. In addition, hypoxanthine is a more specific measure of hypoxia than lactate, base deficit, or $\mathrm{pH}$ and it reflects the intracellular energy status. One group of investigators recently suggested that hypoxanthine should serve as the new "gold" standard for hypoxia. More importantly, evidence is accumulating that hypoxanthine is a better predictor of hypoxic sequelae than other biochemical variables. More prospective studies are needed to confirm this association.

Because hypoxanthine is a potential generator of oxygen radicals, and may be the mediator of posthypoxic reoxygenation injury, it should be useful to monitor plasma hypoxanthine levels in sick patients. New insights into the possible role of hypoxanthine in neurobiology and cancer treatment are expected in the near future, as well as new knowledge of the modulatory effects of hypoxanthine on circulation and respiration. Ten yr ago hypoxanthine was considered to be an inert metabolite, today it 
is acknowledged to play a central role in numerous processes in health and disease.

\section{REFERENCES}

1. Saugstad OD 1975 Hypoxanthine as a measurement of hypoxia. Pediatr Res 9:158-161

2. Jørgensen S, Poulsen HE 1955 On accumulation of hypoxanthine plus xanthine in withdrawn human blood. Acta Pharmacol Toxicol 11:207-211

3. Saugstad OD 1975 The determination of hypoxanthine and xanthine with a $\mathrm{pO}_{2}$ electrode. Pediatr Res 9:575-579

4. Saugstad OD 1987 Purine metabolism in perinatal hypoxia. Perinatol Neonatol 11:20-26

5. McCord JM, Fridovich I 1968 The reduction of cytochrome C by milk xanthine oxidase. J Biol Chem 243:573-560

6. Fridovich I 1970 Quantitative aspects of the production of superoxide anion radical milk xanthine oxidase. J Biol Chem 245:4053-4057

7. Saugstad OD, Aasen AO 1980 Plasma hypoxanthine levels as a prognostic aid of tissue hypoxia. Eur Surg Res 12:123-129

8. Skolnick P, Marangos PJ, Goodwin FK, Edwards M, Paul S 1978 Identification of inosine and hypoxanthine as endogenous inhibitors of $(3 \mathrm{H})$ diazepam binding in the central nervous system. Life Sci 23:1473-1480

9. Liang CM. Liu YP, Chabner BA 1980 Modes of action of hypoxanthine, inosine and inosine 5-monophosphate from bovine brain. Biochem Pharmacol 29:277-282

10. Wung W, Howell SB 1984 Hypoxanthine concentrations in normal subjects and patients with solid tumours and leukemia. Cancer Res 44:3144-3148

11. Atkinson DE 1977 Cellular Energy Metabolism and its Regulation. Academic Press, London

12. Seegmiller JE 1975 Purine metabolism. Arthritis Rheum 18(suppl):681-686

13. al-Khalidi UAS, Chaglassian TH 1965 The species distribution of xanthine oxidase. Biochem J 97:318--320

14. Roy RS, McCord JM 1983 Superoxide and ischemia. Conversion of xanthine dehydrogenase to xanthine oxidase. In: Greenwald R, Cohen G (eds) Oxyradicals and their Scavenging Systems, Vol 2. Cellular and Molecular Aspects. Elsevier Science. New York, pp 145-153

15. McCord JM 1985 Oxygen derived free radicals in postischemic tissue injury N Engl J Med 312:159-163

16. Sørensen LB, Levinson DJ 1975 Origin and extrarenal elimination of uric acid in man. Nephron 14:7-20

17. Levinson DJ, Sørensen LB 1980 Renal handling of uric acid in normal and gouty subjects: incidence for a 4-component system. Ann Rheum Dis 39:173-179

18. Berndt WO 1970 In vitro accumulation of $14 \mathrm{C}$-xanthine by rabbit renal cortex and its relationship to overall oxypurine transport. Nephron 7:339349

19. Harkness RA, Coade SB, Walton KR 1983 Xanthine oxidase deficiency and "dalmatian" hypouricaemia: incidence and effect of exercise. J Inherited Metab Dis 6:114-120

20. Weissmann B, Bromberg PA, Gutman AB 1957 The purine bases of human urin. Il. Semiquantitative estimation and isotope incorporation. J Biol Chem 224:423-434

21. Jensen MH, Jörgensen S 1977 Oxypurine excretion in normal newborn infants. Biol Neonate 32:197-204

22. Saugstad OD, Aasen AO, Hetland $\emptyset 1978$ Plasma hypoxanthine concentrations as an indicator of tissue hypoxia in pigs. Eur Surg Res 10:314-322

23. Thiringer K, Saugstad OD, Kjellmer I 1980 Hypoxanthine as a measure of tissue hypoxia in acutely exteriorized fetal lamb. Pediatr Res 14:905-909

24. Kalckar HM 1947 Differential spectrophotometry of purine compounds by means of specific enzymes. J Biol Chem 167:429-443

25. Jørgensen S, Poulsen HE 1955 Enzyme determination of hypoxanthine and xanthine in human plasma and urine. Acta Pharmacol Toxicol 11:223-243

26. Hayashi $\Upsilon \Upsilon$, Gillo D, Robbins H, Sabbagha RE 1972 Simultaneous measurement of plasma and erythrocyte oxypurines. Gynecol Invest 3:221-236

27. Harkness RA, Simmonds RJ, Coade SB 1984 Effect of hypoxia and exercise on nucleotide metabolism in man. Adv Exp Med Biol 165:437-442

28. Simmonds RJ, Harkness RA 1981 High performance liquid chromatographic methods for base and nucleoside analysis in extracellular fluids and in cells. J Chromatogr 226:369-381

29. Saugstad OD, Rognum TO 1988 High post mortem vitreous hypoxanthine levels in newborns with RDS. Pediatrics (in press)

30. Gardiner DG 1979 A rapid and sensitive fluorimetric assay for adenosine inosine and hypoxanthine. Anal Biochem 95:377-382

31. Sumi T, Umeda Y 1979 Fluorimetric determination of xanthine and hypoxanthine in tissue. Clin Chim Acta 95:291-299

32. Hartwick RA, Brown PR 1976 Evaluation of microparticle bonded reversedphase packing in the high pressure liquid chromatographic analysis of nucleosides and their bases. J Chromatogr 126:679-691

33. Wung WE, Howell SB 1980 Simultaneous liquid chromatography of 5fluorouracil, uridine, hypoxanthine, xanthine, uric acid, allopurinol, and oxypurinol in plasma. Clin Chem 26:1704-1708

34. Boulieu R, Bory C, Baltassat P 1982 High Performance liquid chromatographic determination of hypoxanthine and xanthine in biological fluids. $J$ Chromatogr 233:131-140

35. Niklasson F 1983 Simultaneous liquid- chromatographic determination of hypoxanthine, xanthine, urate, and creatinine in cerebrospinal fluid with direct injection HPLC. Clin Chem 29:1543-1546
36. Lun A, Jung D, Pohle R, Bottcher M, Grauel EL, Gross J 1983 Hypoxanthine konzentration im Blut von Neugeborenem. Z Med Lab Diagn 24:47-52

37. Guicheney P, Zorn J-R, Sureau C, Olive G 1978 Plasma hypoxanthine in neonatal hypoxia: A comparison of two methods. Eur J Obstet Gynecol Reprod Biol 8:89-94

38. O'Connors MC, Harkness RA, Simmonds RJ 1981 The measurement of hypoxanthine, xanthine, inosine, and uridine in umbilical cord blood and fetal scalp blood samples as a measure of fetal hypoxia. Br J Obstet Gynaecol $88: 381-390$

39. Saugstad OD, Wung W, Howell SB, Gluck L 1982 Determination of plasma hypoxanthine: a correlation between HPLC and the $\mathrm{pO}_{2}$ method. Anal Biochem 122:159-163

40. Berne RM 1963 Cardiac nucleotides in hypoxia. Possible role in regulation of coronary blood flow. Am J Physiol 204:317-322

41. Gerlach E, Deuticke B, Dreisbach RH 1963 Zum verhalten von Nucleotiden und ihren dephosporylierte Abbauprodukten in der Niere bei Ischamie und kurzzeitiger postischamischer Wiederdurchblutung. Pflugers Arch 278:296315

42. Berne RM, Rubio R 1974 Adenine nucleotide metabolism of the heart. Circ Res 34/35(suppl) 111:109-120

43. Buhl MR, Jørgensen S 1975 Breakdown of 5'-adenine nucleotides in ischemic renal cortex estimated by oxypurine excretion during perfusion. Scand J Clin Lab Invest 35:211-217

44. Deuticke B, Gerlach E, Dichermann R 1966 Abbau freier nucleotide in Herz, Skeletmuskel, Gehirn und Leber der Ratte bei Sauerstoffmangel. Pflugers Arch 292:239-254

45. Kleihues P, Kobayashi K, Hossmann KA 1974 Purine nucleotide metabolism in the cat brain after one hour of complete ischemia. J Neurochem 23:417425

46. Saugstad OD, Schrader H 1978 The determination of inosine and hypoxanthine in rat brain during normothermic and hypothermic anoxia. Acta Neurol Scand 57:281-288

47. Remme WJ, de Jong JW, Verdouw PD 1977 Effects of pacing-induced myocardial ischemia on hypoxanthine efflux from the human heart. Am J Cardiol 40:55-62

48. Cunningham SK, Keaveny TV 1977 Splanchnic organ adenine nucleotides and their metabolites in haemorrhagic shock. Ir J Med Sci 146:136-143

49. Mentzer RM, Rubio R, Berne RM 1975 Release of adenosine by hypoxic canine lung tissue and its possible role in pulmonary regulation. Am J Physiol 229:1625-1631

50. Simmonds RJ, Coade SB, Harkness RA, Drury L, Hytten FE 1982 Nucleotide, nucleoside and purine base concentrations in human placentae. Placenta 3:29-38

51. Spann WK, Gröbner W, Zöllner N 1980 Effect of hypoxanthine in meat on serum uric acid and urinary acid excretion. In: Rapado A, Watts RWE, De Bruyn CHMM (eds) Purine Metabolism in Man, Vol 111. Clinical and Therapeutic Aspects. Plenum Press, New York, pp 215-219

52. Saugstad OD, Bø G, Østrem T, Aasen AO 1977 Hypoxanthine levels of plasma during hypoxemia in dogs. Eur Surg Res 9:23-33

53. Saugstad OD, Østrem T 1977 Hypoxanthine and urate levels of plasma during and after hemorrhagic hypotension in dogs. Eur Surg Res 9:48-56

54. Aasen AO, Saugstad OD 1979 Washing out of hypoxanthine in terminal endotoxin shock in dogs. Circ Shock 6:277-283

55. Saugstad OD, Schrader H, Aasen AO 1976 Alteration of the hypoxanthine level in cerebrospinal fluid as an indicator of tissue hypoxia. Brain Res 112:188-189

56. Moss M, Kurzner S, Razlog Y, Lister G 1986 Hypoxanthine and lactate during oxygen deficiency in lambs. Pediatr Res 20:181A

57. Thiringer K, Blomstrand S, Hrbek A, Karlsson K, Kjellmer I 1982 Cerebral arterio-venous difference for hypoxanthine and lactate during graded asphyxia in the fetal lamb. Brain Res 239:107-117

58. Thiringer K, Karlsson K, Rosen KG, Kjellmer I 1984 The contribution of heart muscle, liver, skeletal muscle and placenta to the elevation of hypoxanthine during asphyxia in the acutely exteriorized foetal lamb. Biol Neonate 45:169-182

59. Lipp Zwahlen AE, Tuchschmid P, Silberschmid M, Duc G 1983 Arterial cord blood hypoxanthine: A measure of intrauterine hypoxia? Biol Neonate 44:193-202

60. Thiringer K 1983 Cord plasma hypoxanthine as a measure of foetal hypoxia. Acta Paediatr Scand 72:231-237

61. Mechurova A, Stipek S, Novak L, Trojan S 1985 The hypoxanthine level in cord blood. A potential indicator of foetal hypoxia. Physiol Bohemoslov $35: 174-176$

62. Saugstad OD, Ziegler M, Kessel B, Saunders B, Gluck L 1986 Correlation of plasma hypoxanthine and catecholamine levels in the umbilical vein. J Perinat Med 14:339-343

63. Pietz J, Guttenberg N, Gluck L 1987 Hypoxanthine: new standard for asphyxia. Pediatr Res 21:373A

64. Issel EP, Lun A, Pohle R, Gross J 1987 Hypoxanthine plasma concentration in pregnancy and labour with regard to hypoxia. J Perinat Med (in press)

65. Wallenburg HCS, Van Kreel BK 1980 Maternal and umbilical plasma concentrations of uric acid and oxypurines at delivery in normal and hypertensive pregnancy. Arch Gynecol 229:7-11

66. Bratteby LE, Swanström S 1982 Hypoxanthine concentration in plasma during the first two hours after birth in normal and asphyxiated infants. Pediatr Res 16:152-155

67. Swanström S, Bratteby LE 1982 Hypoxanthine as a test of perinatal hypoxia 
as compared to lactate, base deficit and $\mathrm{pH}$. Pediatr Res 16:156-160

68. Jung D, Lun A, Zinsenmeyer J, Grauel EL, Gross J 1985 The concentration of hypoxanthine and lactate in the blood of healthy and hypoxic newborns. J Perinat Med 13:43-49

69. Karmazsin L, Balla B 1985 Plasma hypoxanthine and xanthine levels in the early newborn period in problem-free preterm babies and those with idiopathic respiratory distress syndrome. Acta Paediatr Hung 26:1-9

70. Lun A, Pohle R, Hartwig A, Ihle W, Gross J 1980 Verhalten der hypoxanthinkonzentration im Plasma bei Neugeborenen Kindern mit Herzfehlern. Dtsch Gesundh Wesen 35:1006-1009

71. Saugstad OD, Gluck L 1982 Plasma hypoxanthine levels in newborn infants: a specific indicator of hypoxia. J Perinat Med 10:266-272

72. Grum CM, Simon RH, Dantzher DR, Fox IH 1985 Evidence for adenosine triphosphate degradation in critically ill patients. Chest 88:763-767

73. Schoenberg MH, Fredholm BB, Hohlbach G 1985 Changes in acid-base status, lactate concentration and purine metabolites during reconstructive aortic surgery. Acta Chir Scand 151:227-233

74. Møller-Petersen J, Andersen PT, Hjørne N, Ditzel J 1985 Hyperamylasemia, specific pancreatic enzymes, and hypoxanthine during recovery from diabetic ketoacidosis. Clin Chem 31:2001-2004

75. Møller-Petersen J, Andersen PT, Ditzel J 1986 Nontraumatic rhabdomyolysis during diabetic ketoacidosis. Diabetologia 29:229-234

76. Knudsen F, Andersen PT 1985 Cellular hypoxia during hemodialysis. Demonstration of intradialytic release of purine and pyrimidine metabolites. Blood Purific 3:179-183

77. Sørlie D, Myhre K, Saugstad OD, Gierscky K 1982 Hypoxanthine levels of exercising patients with claudicatio intermittens. Acta Med Scand 211:281286

78. Manzke H, Dörner K, Grünitz J 1977 Urinary hypoxanthine, xanthine and uric acid excretion in newborn infants with perinatal complications. Acta Paediatr Scand 66:713-717

79. Harkness RA, Simmonds RJ, Coade SB, Lawrence CR 1983 Ratio of the concentration of hypoxanthine to creatinine in urine from newborn infants: A possible indicator for the metabolic damage due to hypoxia. $\mathrm{Br} \mathrm{J}$ Obstet Gynaecol 90:447-452

80. Harkness RA, Whitelaw AGL, Simmonds RJ 1982 Intrapartum hypoxia: the association between neurological assessment of damage and abnormal excretion of ATP metabolites. J Clin Pathol 35:999-1007

81. Buhl L, Vilhelmsen KN, Rohnedal Nielsen J 1981 Oxypurine release in cardiac disease. Acta Med Scand 209:83-86

82. Wooliscroft JO, Fox IH 1986 Increased body fluid purine levels during hypotensive events. Am J Med 81:472-478

83. Sweetman L 1968 Urinary and cerebrospinal fluid oxypurine levels and allopurinol metabolism in the Lesch-Nyhan syndrome. Fed Proc 27:10051059

84. Meberg A, Saugstad OD 1978 Hypoxanthine in cerebrospinal fluid in children. Scand J Clin Lab Invest 38:437-440

85. Manzke H, Staemmler W, Dorner K 1981 Increased nucleotide catabolism after cerebral convulsions. Neuropediatrics 12:119-131

86. Manzke H, Staemmler W 1981 Oxypurine concentration in the CSF in children with different diseases of the nervous system. Neuropediatrics $12: 209-214$

87. Harkness RA, Lund RJ 1983 Cerebrospinal fluid concentrations of hypoxanthine, xanthine, uridine and inosine: high concentrations of the ATP metabolite hypoxanthine after hypoxia. J Clin Pathol 36:1-8

88. Bejar R, Saugstad OD, James H, Gluck L 1983 Acute hydrocephalus in the newborn evaluated with ultrasound and CSF hypoxanthine levels. J Pediatr 103:44-48

89. Levin SD, Brown JK, Harkness RA 1984 Cerebrospinal fluid hypoxanthine and xanthine concentrations as indicators of metabolic damage due to raised intracranial pressure in hydrocephalic children. J Neurol Neurosurg Psychiatry 47:730-733

90. Castro-Gago M, Lojo S, Del Rio R, Rodriquez A, Novo I, Rodriquez-Segade S 1986 The concentrations of xanthine and hypoxanthine in cerebrospinal fluid as a therapeutic guide in hydrocephalus. Child Nerv Syst 2:109-111

91. Bøhmer T, Kjekshus J, Vaagenes P 1983 Biochemical indices of cerebra ischemic injury. Scand J Clin Lab Invest 43:261-265

92. Harkness RA, Geirsson RI, Mc Fadyen IR 1983 Concentrations of hypoxanthine, xanthine, uridine and urate in amniotic fluid at caesarean sectio and the association of raised levels with prenatal risk factors and fetal distress. $\mathrm{Br}$
J Obstet Gynaecol 90:815-820

93. Saugstad OD, Olaisen B 1978 Post mortem hypoxanthine values in the vitreous fluid. Forensic Sci Int 12:33-36

94. Saugstad OD 1983 Hypoxanthine and the diagnosis of hypoxia. Ups J Med Sci [Suppl] 38:29-33

95. Andreoli SP, Clark JH, McCuire WA, Bergstein JM 1986 Purine excretion during tumor lysis in children with acute lymphocytic leukemia receiving allopurinol:Relationship to acute renal failure. J Pediatr 109:292-298

96. Zimm S, Johnson G, Poplack DG 1986 Modulation of thiopurine cytotoxicity in the HL-60 cell line by physiological concentrations of hypoxanthine. Cancer Res 46:6286-6289

97. Lapin IP 1981 Nicotinamide, inosine and hypoxanthine, putative endogenous ligands of the benzodiazepine receptor, opposite to diazepam are much more effective against kynurenine-induced seizures than against pentylenetetrazole-induced seizures. Pharmacol Biochem Behav 14:589-593

98. Levin E 1983 Inosine, hypoxanthine and seizures. In: Delgado-Escueta AV Wasterland CG, Treiman DM, Porter RJ (eds) Advances in Neurology, Vol 34. Raven Press, New York, pp 365-367

99. Niklasson F, Ảgren H, Hallgren R 1983 Purine and monoamine metabolites in cerebrospinal fluid: parallel purinergic and monoaminergic activation in depressive illness? J Neurol Neurosurg Psychiatry 46:255-260

100. Ågren H, Niklasson F, Hallgren R 1983 Brain purinergic activity linked with depressive symptomatology: hypoxanthine and xanthine in CSF of patients with major depressive disorders. Psychiatry Res 9:179-189

101. Fredholm BB, Hedquist P 1980 Modulation of neurotransmission by purine nucleotides and nucleosides. Biochem Pharmacol 29:1635-1643

102. Fridovich I 1979 Hypoxia and oxygen toxicity. In: Fahn S (ed) Advances in Neurology, Vol 26. Raven Press, New York, pp 255-259

103. Granger DN, Rutili G, McCord JM 1981 Superoxide radicals in feline intestinal ischemia. Gastroenterology 81:22-29

104. Schoenberg MH, Fredholm BB, Haglund K, Jung H, Sellin D, Younes M, Schildberg FW 1985 Studies on the oxygen radical mechanism involved in the small intestinal reperfusion damage. Acta Physiol Scand 124:581-589

105. Saugstad OD, Hallman M, Abraham J, Cochrane CG, Epstein B, Gluck L 1984 Hypoxanthine and oxygen induced lung injury: a basic mechanism of tissue damage? Pediatr Res 18:501-504

106. Saugstad OD, Becher G, Grossmann M, Oddoy A, Merker G, Lachmann B 1987 Acute and chronic lung damage in guinea pigs induced by xanthine oxidase. Intensive Care Med 13:30-32

107. Parks DA, Bulkley GB, Granger DN 1983 Role of oxygen-derived free radicals in digestive tract disease. Surgery $94: 415-422$

108. Gardner TJ, Stewart JR, Casale AS, Downey JM, Chambers DE 1983 Reduction of myocardial ischemic injury with oxygen derived free radical scavengers. Surgery 94:423-427

109. Poulsen JP, Bjøro K, Kreyberg S, Saugstad OD 1986 Oxygen radicals stimulate prostaglandin synthesis in the rat small intestine. Pediatr Res 20:1036(abstr)

110. Warso MA, Lands WEM 1983 Lipid peroxidation in relation to prostacyclin and thromboxane physiology and pathophysiology. Br Med Bull 39:277280

111. Tate RM, Morris HB, Schroeder WB, Repine JE 1984 Oxygen metabolites stimulate thromboxane production and vasoconstriction in isolated saline perfused rabbit lungs. J Clin Invest 74:608-613

112. Autor AP, Frank L, Roberts RJ 1976 Developmental characteristics of pulmonary superoxide dismutase: relationship to idiopathic respiratory distress syndrome. Pediatr Res 10:154-158

113. Tanswell AK, Freeman BA 1984 Pulmonary antioxidant enzyme maturation in the fetal and neonatal rat. 1. Developmental profiles. Pediatr Res 18:584587

114. Gerdin E, Tyden O, Erikson UJ 1985 The development of antioxidant enzymatic defense in the perinatal rat lung. Activities of superoxide dismutase, glutathione peroxidase and catalase. Pediatr Res 19:687-691

115. Andersen PT, Bacher T, Stentoft J 1986 Hypoxanthine and xanthine in stored SAGM blood. Scand J Haematol 37:59-62

116. Hittner HM, Kretzer FL 1986 Efficacy of vitamin $E$ in retinopathy of prematurity. In: McPherson AR, Hittner HM, Kretzer FL (eds) Retinopathy of Prematurity. B. C. Decker Inc., Toronto, pp 89-103

117. Saugstad OD 1985 Oxygen radicals and pulmonary damage. Pediatr Pulmonol 1:167-175 